\title{
Criar o público não-estatal ou tornar público o estatal? Dilemas da educação em meio à crise do Estado
}

\author{
Márcio da Costa
}

Universidade Federal do Rio de Janeiro, Faculdade de Educação

\section{Introdução}

Presentemente, diversificam-se as formas de distribuição de recursos e responsabilidades, no que concerne às políticas educacionais. Particularmente, nos países com menor grau de desenvolvimento econômico, esse âmbito de tradicional ação estatal tem sido objeto de apelos destacados e políticas expressivas de estímulo à participação comunitária. Este artigo pretende discutir tal situação, a partir de minha própria experiência.

* O presente artigo é fruto de uma reflexão pessoal pouco ambiciosa, extraída de uma experiência vivida há mais de dez anos e atualizada por observações acerca de políticas educacionais contemporâneas. Não se inclui entre os temas que venho pesquisando recentemente. Por isso, não houve preocupação em rever a literatura recente sobre o assunto, exceto no que diz respeito às descrições de programas recentemente criados, o que em muito o enriqueceria, conforme bem apontado pelo(a) parecerista da Revista Brasileira de Educação, a quem muito agradeço pelos preciosos comentários e sugestões, às quais pude atender apenas algumas.
De 1987 a 1988, vivi a experiência de coordenar um grande programa da prefeitura da cidade do Rio de Janeiro, que tinha como intenção apoiar iniciativas comunitárias de constituição de pré-escolas, em regiões concentradoras de populações bastante pobres - as favelas e loteamentos irregulares que se espalham por toda a cidade. Um verdadeiro movimento de escolas deste gênero formara-se, então, abrangendo até mesmo articulações de nível nacional, dado que as assim chamadas escolas comunitárias não eram um fenômeno circunscrito a uma região particular.

Esta experiência, muito rica e polêmica, levoume a buscar uma compreensão mais sólida das circunstâncias encontradas e dos arranjos sociais e políticos envolvidos. Mais recentemente, novas iniciativas que podem ser consideradas tributárias daquelas anteriores, agora não mais promovidas apenas por estruturas governamentais de nível municipal, têm adquirido importância destacada no âmbito das políticas educacionais, inclusive em nível internacional. São programas de extensão do acesso à escolaridade para populações até então privadas de tal benefício, como aqueles 
levados adiante em diversos países da América Central ou mesmo programas voltados para a intervenção em sistemas escolares já existentes, mas que enfatizam a alteração nas formas de gestão, voltando-as para esquemas de estímulo à participação comunitária. No limite, tais programas e projetos alteram a trajetória cumprida tradicionalmente pelos sistemas escolares em sua expansão ao redor do mundo, no que diz respeito à sua concepção de atividade essencialmente estatal. As propostas na agenda educacional ora em pauta não são semelhantes aos modelos que se desenvolveram na experiência mencionada - as escolas comunitárias. Porém, guardam aspectos de fundo que podem ser discutidos à luz daquelas iniciativas. Conforme pretendo expor, tais programas de inspiração participativa forjam um modelo específico de ação estatal, produzem ou promovem novos atores sociais, reforçam algumas elites políticas, geram impactos variáveis sobre os sistemas educacionais constituídos e, sobretudo, tornamse uma peça destacada nos discursos políticos de alguns governos. As críticas e restrições a iniciativas de tal perfil costumam ser bastante tímidas, pois o discurso enfático acerca da participação como aspecto central da democracia tende a ser referendado nos dias atuais por quase todos os participantes mais ativos nas arenas políticas.

Por outro lado, se a distribuição de encargos pelo estado em direção a empresas privadas é alvo de ferrenha oposição por parte de grupos políticos que combatem as políticas de privatização, a mesma distribuição de serviços públicos entre associações comunitárias, ou as chamadas ONG's, não é objeto do mesmo tipo de reação acalorada. Pode-se mesmo dizer que uma certa valorização positiva, que setores da esquerda atribuíram a iniciativas e organizações de caráter comunal, tem sido fortemente incorporada por forças tradicionalmente identificadas como estando à direita do espectro político. Parece haver uma quase unanimidade em torno de políticas - as mais diversas - encetadas para ampliar a incorporação, o prolongamento da permanência ou a mudança em padrões no atendimento educacional de populações historicamente alijadas (ou muito precariamente incluídas) de tal direito elementar. ${ }^{1} \mathrm{O}$ fato de tais políticas recorrerem a formas de gestão e organização que apelam para uma participação mais ativa da clientela envolvida e/ou alteram padrões clássicos dos serviços públicos tem sido recebido ora com aquiescência ora com entusiasmo, mas raramente tem sido objeto de crítica consistente.

O objetivo deste trabalho é discutir a representação de tais programas como panacéia, levantar hipóteses sobre possíveis externalidades negativas que engendram sem, no entanto, desqualificar suas potencialidades virtuosas. Trata-se de um esforço por levantar dúvidas, mais que por buscar demolir argumentos. O questionamento aqui expresso procurará se confrontar com a concepção de democracia contida em tais proposições e, principalmente, discutir as bases sociológicas da idéia de comunidade como instância superior de exercício democrático e maximização de benefícios no âmbito dos serviços públicos. Os elementos presentes em nossa análise são tributários de uma tradição que destaca a democratização como um processo de universalização de regras e procedimentos, bem como do senso de pertencimento a uma comunidade política não circunscrita aos limites do local nem do comunal. Considero, também, na trajetória de constituição da modernidade organizada, ${ }^{2}$ sua crise contemporânea como embate promovido por forças que sempre estiveram presentes nos conflitos entre os valores de ampliação e de constrangimento da marcha de aquisição de direitos, exposta por Marshall (1967) e cujo debate é tão bem sumariado por Hirschman (1992).

\section{Público não-estatal, uma nova forma de comunitarismo?}

A hipótese de análise que aqui pretendo desenvolver procura explorar as ligações possíveis entre al-

${ }^{1}$ A noção da educação como um direito básico associado à cidadania parece não mais encontrar opositores no mundo contemporâneo ocidental. Em outros contextos da Ásia e África, contudo, restrições severas manifestam-se sobre as mulheres.

2 Ver Wagner (1994). 
guns esquemas amplamente defendidos no momento atual - os quais propugnam uma gestão fortemente descentralizada e a transferência de responsabilidades dos níveis centrais da administração educacional estatal para níveis inferiores como solução central para as mazelas que assolam os sistemas escolares, especialmente aqueles destinados ao atendimento das populações pobres - e antigas matrizes de política educacional presentes naquilo que doravante nomearei "comunitarismo". ${ }^{3}$ Uma forma contemporânea sob a qual tal matriz se manifesta costuma denominar uma nova instância: o "público não-estatal". ${ }^{4}$

Antes, porém, de mergulhar com maior profundidade nesta questão, é necessário delimitar mais precisamente o problema em foco.

Recente seminário organizado pelo Programa de Reforma Educacional na América Latina (PREAL) ${ }^{5}$ demonstrou com nitidez as ênfases que os processos de gestão escolar adquiriram no âmbito das políticas educacionais de boa parte dos países do mundo ocidental. Programas se constroem em diversos contextos, amparados na idéia de que a descentralização administrativa, o apelo à participação comunitária e a gestão da rede escolar a partir das unidades escolares comporiam um núcleo central das políticas de recuperação dos sistemas educacionais anacrônicos e ineficientes que são característicos de inúmeros países, principalmente do mundo subdesenvolvido. Ainda que alguns alertas quanto ao pretenso poder das políticas descentralizadoras da gestão educacional já

${ }^{3}$ A esse respeito, ver Cunha (1991), especialmente o cap. 10, que contém discussão acerca do comunitarismo e relata com razoável precisão a trajetória do programa de apoio às escolas comunitárias, que serve de ponto de partida deste artigo.

${ }^{4} \mathrm{O}$ termo em língua inglesa "public non-governmental” não incorpora exatamente a mesma conotação que se disseminou em português, pois a distinção entre governo e estado parece ser importante, neste caso.

${ }^{5}$ Seminário Internacional de Autonomia e Gestão Escolar na América Latina: oportunidades, obstáculos e condições. Recife, Brasil, maio de 2000. venham ocorrendo há algum tempo, ${ }^{6}$ estas gozam de grande destaque entre as receitas predominantes de gestão, atualmente.

De qualquer forma, no meio de diagnósticos e proposições educacionais, ganhou destaque aquela que se tornou a peça central das novas tendências na política educacional: o discurso acerca da democratização dos meios de gestão do sistema escolar, por via da descentralização de decisões em direção aos usuários diretos do sistema. Sob diversos aspectos, esta forma de abordar o problema educacional guarda parentesco com um modelo que se instalou, no Brasil e em outros países periféricos, ao final dos anos 70 e prolongou-se ao longo dos 80. Tal modelo adquiriu a denominação genérica de "escolas comunitárias". Há, porém, inúmeras diferenças entre as propostas agora apresentadas e aquelas desenvolvidas então.

Em primeiro lugar, as escolas comunitárias típicas dos anos 70/80 expandiram-se sob a égide de dois tipos de motivações bem distintas. Por um lado, o forte discurso antiescolar, amparado em toda uma avalanche de análises que caracterizavam os sistemas educacionais sobretudo como aparelhos de dominação social e reprodução do status quo, ${ }^{7}$ engendrou a criação de alternativas aos sistemas escolares oficiais, por parte de grupos intelectuais e políticos que buscavam combater o capitalismo e os regimes que com este sistema econômico comungavam. Por outro lado, agências internacionais (como o UNICEF), associações religiosas, entidades filantrópicas e agências internas a máquinas estatais estimulavam um certo tipo de comunitarismo, como forma de expandir o atendimento educacional a setores sociais excluídos do acesso a ele. Desta conjugação de tendências, impulsionada pelas imensas carências no atendimento educacional (especialmente no segmento da pré-escola) aos con-

\footnotetext{
${ }^{6}$ Ver McGinn (1992).

${ }^{7}$ Não creio ser necessário alinhar a infinidade de trabalhos que se celebrizaram pelo tratamento do sistema escolar como via privilegiada de reprodução do capitalismo, por meio, principalmente, dos artifícios da ideologia.
} 
tingentes mais pobres da população, brotaram muitas experiências de escolas organizadas e geridas no âmbito bastante restrito das localidades com menor acesso aos serviços públicos, inclusive ao educacional. Em algumas circunstâncias, verdadeiras redes escolares paralelas aos sistemas estatais se formaram, amparadas por discursos ora numa linha includente de "desenvolvimento comunitário", ora adotando posições de ruptura com os esquemas públicos tradicionais. Freqüentemente, produziram-se combinações sincréticas no nível da argumentação. Todavia, a afirmação da supremacia da gestão local, da participação comunitária, do controle dos usuários do sistema sobre os serviços prestados era uma tônica constante em praticamente todos os discursos. O suposto maior grau de democracia que tais iniciativas desenvolveriam seria o diferencial essencial que lhes garantiria um alto grau de vantagem (política e técnica) sobre os arranjos tradicionais sob os quais a escola de massas se expandiu e consagrou-se.

Ocorreu, portanto, um processo simultâneo de desvalorização das redes escolares públicas - ora com ênfase na má qualidade e no insuficiente alcance dos serviços que prestavam ora com destaque para suas dimensões ideológicas conservadoras e antipopulares - e de afirmação de uma alternativa superior, centrada no formato da gestão escolar. Um dos resultados desse processo foi a proliferação de um modelo de escola híbrido, no qual parte da sustentação advinha de recursos públicos (estatais), mas cujos mecanismos de controle e gestão obedeciam a procedimentos muito distintos daqueles consagrados nas escolas públicas.

Talvez não seja correto falar de um modelo de escola comunitária e de políticas forjadas para lidar com elas. Afinal, havia uma grande diversidade de tais escolas, seja nas motivações com que foram criadas, seja na forma como eram concebidas e geridas, seja, ainda, nos formatos institucionais que adotaram ou nos padrões de relacionamento com o aparato estatal.

A parcela dos recursos com que o estado participava na sustentação financeira de tais iniciativas variava imensamente, indo de montantes quase insignificantes até a sustentação quase completa de seus custos regulares. ${ }^{8}$ As formas de interação entre tais empreendimentos e a máquina estatal também apresentavam grande variação. ${ }^{9}$ A intermediação de agentes externos e os contextos políticos a que tais iniciativas se vinculavam compunham quadros bastante diversos sobre os quais as experiências se desenvolveram, bem como as condições socioeconômicas formavam panos de fundo distintos, que acentuavam ou atenuavam o peso relativo que aquelas desempenhavam nas comunidades em que se inseriam. ${ }^{10}$ Também o tipo de orientação político-ideológica que as presidia apresentava alguma diversidade.

Porém, todas as experiências que pude conhecer se caracterizavam por estarem destinadas a populações que ocupavam posições inferiores nas estruturas de distribuição de renda e prestígio em suas sociedades. Outra marca distintiva era a evidente insuficiência na cobertura escolar que os sistemas públicos (ou privado) de mais larga abrangência apresentavam no atendimento às populações que eram objeto de tais iniciativas e programas. Deve-se assinalar que os graus de institucionalização que os estados produziram para lidar com tal fenômeno foram imensamente diferentes. Assim, desde a hostilidade e/ou desprezo até o estímulo (velado ou aberto) para que esse modelo de escola se difundisse, variados matizes se constituíram neste aspecto. Em algumas (poucas) circunstâncias, verdadeiros programas de sustentação foram gerados, configurando autênticas redes paralelas de escolas, sob forte patrocínio público, mas obedecendo a regras e

${ }^{8}$ Do fornecimento de alguns materiais de trabalho e/ou merenda escolar até a contratação de professoras e a construção de prédios, assistência técnica e o estabelecimento de relações permanentes que garantiam estabilidade ao trabalho.

${ }^{9}$ De concepções mais próximas à concessão de um favor até o reconhecimento de um direito.

${ }^{10}$ A intermediação de lideranças locais ou de representantes parlamentares freqüentemente interferia na relação com o poder público. Este, por sua vez, também tinha atitudes distintas quanto às escolas comunitárias, segundo o tipo de orientação política adotado. Este ponto será desenvolvido mais adiante. 
procedimentos em muito diferentes daqueles a que as escolas "normais" deveriam se curvar.

Foi exatamente num programa de tal tipo que tive a oportunidade de desenvolver questões que apresentarei mais adiante. Considero relevante recuperar a memória de tal experiência por perceber que há similitudes entre o modelo então desenvolvido e aqueles que ora se constroem. Por ora, é interessante apresentar um breve resumo da experiência em foco, secundado pelas reflexões que ela me suscitou.

\section{As escolas comunitárias do Rio de Janeiro e a política gerada em sua intenção}

Historicamente, é bastante baixo o índice de atendimento educacional a crianças em idade anterior à escolarização obrigatória. Na década de 1980, no Rio de Janeiro, menos de $15 \%$ das crianças de 0 a 6 anos de idade encontravam algum tipo de atendimento em pré-escolas e creches, públicas ou privadas. Em 1984, quando a experiência aqui relatada adquiria seus contornos mais definidos, pouco mais de 30 mil crianças ${ }^{11}$ - em um universo de cerca de 250 mil $^{12}$ - contavam com matrículas na rede pública de ensino da cidade do Rio de Janeiro (uma das mais abrangentes redes escolares do país).

Essa carência é especialmente sentida entre aqueles setores sociais em que a participação feminina no mercado de trabalho foi se tornando cada vez mais imprescindível à sustentação das famílias. Ao final dos anos de 1970, os prenúncios da crise econômica, que poucos anos mais tarde se abateria de forma dramática sobre os setores mais pobres da sociedade brasileira, conjugavam-se ao esgotamento da ditadura militar, impulsionando demandas populares ${ }^{13}$ até então sufocadas

${ }^{11}$ MEC, Censo Escolar.

${ }^{12}$ Estimativa a partir da PNAD - IBGE.

${ }^{13}$ Os movimentos de mulheres surgem como uma dessas expressões contextuais. Não desempenharam, contudo, papel mais destacado no processo de formação das escolas comunitárias no Rio de Janeiro, exceto pela inclusão na agenda de preocupações com a situação da mulher trabalhadora. pelo controle autoritário imposto pelo regime. Nesse quadro, esquematicamente sumariado, encontram-se as condições que alimentaram o movimento de criação de escolas comunitárias, para o atendimento das crianças pequenas, em algumas favelas do Rio de Janeiro. Resumindo: ingresso acelerado de mulheres no mercado de trabalho; perda acentuada de rendimentos entre os setores sociais mais pobres; aquecimento do mercado eleitoral; retomada dos movimentos reivindicatórios por direitos sociais, ao lado de baixíssima cobertura dos serviços públicos de educação pré-escolar - estas podem ser consideradas características estruturais que contribuíram para o surgimento de algo que pode ser caracterizado como uma rede escolar pública não-estatal.

De forma improvisada, apoiando-se em laços de parentesco e vizinhança, alguns grupos de residentes em favelas da cidade tomaram a iniciativa de criar escolas comunitárias e, simultaneamente, começaram a pressionar a administração pública no sentido de apoiar em alguma medida a experiência. Contando com apoio inicial da UNICEF, tais escolas beneficiaram-se do contexto nacional em que a emergência de novos movimentos sociais se combinava com os ares de redemocratização do país e um clima social favorável às demandas dos segmentos longamente excluídos dos benefícios do desenvolvimento econômico acelerado das décadas anteriores. A aproximação da retomada de eleições ${ }^{14}$ para os governos estaduais e municipais trazia também um elemento que reforçaria a adoção de políticas que contemplassem em algum grau os largos contingentes populacionais mais pobres: a atenção de elites políticas, voltada novamente à obtenção de bases de sustentação em meio a populações portadoras de grande número de votos e completamente novatas na aquisição de prerrogativas e direitos sociais. ${ }^{15}$ No

\footnotetext{
${ }^{14} \mathrm{O}$ que aconteceu em 1982.

${ }^{15}$ Não quero afirmar que as ditaduras prescindem da busca
} de apoio popular. Porém, a redução ou supressão do mercado eleitoral faz com que as elites políticas conservadoras disponham de outros meios de buscar vantagens, olhando "para cima" e dependendo menos dos que estão bem "abaixo". 
mercado político eleitoral reconstituído, a moeda das pré-escolas gozava de grande valor. Processos semelhantes desenrolaram-se em diversas partes do país e o próprio governo federal deu início a um grande programa federal de atendimento pré-escolar, em 1981, por meio do MOBRAL. ${ }^{16}$

Em verdade, o movimento de escolas comunitárias pode ser considerado também, ao menos parcialmente, herdeiro de experiências como as desencadeadas sob a inspiração de Paulo Freire, nos anos de 1960. Assim como as iniciativas dos anos de 1960, inspiradas nas idéias deste grande pensador da educação, incorporavam um forte discurso crítico à escola tradicional, também as escolas comunitárias dos anos de 1980 (especialmente as primeiras, nas quais a força de ruptura do carisma atuava de forma contundente) traziam em sua motivação um certo orgulho de serem "escolas do povo".

Muito rapidamente o "movimento" alastrou-se, contando com um estímulo poderoso: um programa criado na prefeitura da cidade, especificamente voltado para atender às escolas comunitárias recém-criadas. Criado em 1980, de forma muito tímida, para dar conta de um número bem reduzido de unidades (menos de 10), o programa expandiu-se em ritmo acelerado, trazendo uma linha política que o caracterizou de forma marcante. Denominarei este estilo de fazer política pública como "neopopulismo".

De maneira muito geral, podemos considerar o populismo como um estilo de atuação política e uma forma da estabelecer laços políticos que tratam como concessões e favores elementos que historicamente têm sido considerados direitos, especialmente os direitos sociais. A distribuição de tais "favores" está associada a procedimentos de arregimentação de fidelidades políticas, baseadas na cooptação de indivíduos que se destacam por alguma forma de liderança, em meios sociais pouco influentes. O processo de cooptação é uma via de mão dupla, na qual tais lideranças contam com formas

${ }^{16}$ Movimento Brasileiro de Alfabetização, fundação criada na década de 1970 para enfrentar o problema das altas taxas de analfabetismo adulto. de relacionamento personalizado e com o recebimento de algum tipo de vantagem a ser discricionariamente distribuído entre suas "clientelas". Os termos "fisiologismo" e "clientelismo" foram usados para caracterizar tais padrões de relacionamento entre ocupantes do poder público e articuladores de suas bases de sustentação eleitoral, estando quase sempre associados ao que ficou consagrado na literatura política e sociológica como "populismo" - comportamento característico de governo em alguns países que experimentaram a incorporação de grandes massas rurais à polis, após o período colonial e com a modernização acelerada de alguns aspectos de sua vida socioeconômica, ao longo do século XX.

Esse estilo de relacionamento entre os ocupantes do poder público e os setores sociais marginalizados foi adquirindo contornos claros. As escolas comunitárias iniciais passaram a contar com um apoio sistemático por parte de uma secretaria municipal especificamente criada para cuidar dos serviços públicos em áreas de grande concentração de moradores de baixa renda (as favelas e ocupações irregulares que se espalham por toda a cidade, condensando cerca de $20 \%$ da população). Tal secretaria pode ser compreendida como fazendo parte de um esquema voltado para uma dupla tarefa. A primeira seria oferecer alguns serviços públicos (creches e pré-escolas, obras de saneamento, contenção de encostas, arruamento, ações preventivas na área médica) a esses setores populares, residentes de áreas onde tais serviços nunca estiveram disponíveis. A segunda tarefa seria estabelecer vínculos e controles com os nascentes movimentos de moradores de tais localidades, procurar cooptar suas lideranças e arregimentar fidelidades para com os esquemas de poder instituídos.

Em poucos anos, o número de escolas e o de crianças atendidas cresceu exponencialmente. Ao final de 1988, mais de 350 escolas e cerca de 30 mil crianças estavam inscritas no programa de apoio que a administração municipal legou às escolas comunitárias. ${ }^{17}$

${ }^{17} \mathrm{O}$ atendimento concentrava-se em crianças na faixa dos três aos seis anos, mas existiam também creches. Na maior parte dos casos, as unidades vinculadas ao programa trabalhavam em regime de horário integral. 
Passado o período inicial, a trajetória de criação de tais escolas seguiu quase sempre o mesmo figurino. Sabendo da existência do programa, grupos locais articulavam a criação de escolas em ritmo acelerado, buscando posteriormente obter o apoio da Prefeitura.

O tipo de apoio fornecido também foi se alterando progressivamente. Ainda que marcado por evidente preocupação com a contenção dos custos, houve um aumento considerável nos itens financiados pela prefeitura. ${ }^{18}$ Construído à margem de qualquer planejamento racional, o programa de apoio às escolas comunitárias jamais teve metas a serem cumpridas. Sua expansão se deu de forma desordenada, obedecendo em grande parte à lógica e aos interesses partidários e eleitorais dos secretários municipais a que estava subordinado. Tornou-se, também, um grande balcão de atendimento de demandas, de acordo com a capacidade organizativa e com os vínculos políticos das elites locais. Assim, algumas localidades logravam obter apoio a mais de uma escola comunitária, enquanto outras passavam muito tempo sem qualquer resposta a sua demanda. Durante todos os anos iniciais (de 1980 a 1987), jamais houve qualquer critério claro para a concessão ou rejeição do apoio às escolas que o solicitavam. Geralmente, a decisão derivava de algum tipo de avaliação política.

Pode-se dizer que a expansão do programa atendia muito mais à agenda política dos secretários e chefes intermediários do que a uma perspectiva de atendimento de um direito básico da população. As crianças e as condições em que seriam atendidas também não eram elemento central nas decisões tomadas. Prédios e instalações em condições muito diversas - às vezes

${ }^{18}$ Inicialmente, o Programa de Educação Comunitária restringia-se à contratação de "agentes comunitários" - pessoas contratadas nas comunidades para cuidar das crianças atendidas. Com o desenvolvimento, o apoio oferecido passou a ser bem mais abrangente, envolvendo desde o envio de materiais pedagógicos, equipamentos utilitários, mobiliário, alimentação, cuidados com as instalações físicas e, por fim, sistemático acompanhamento técnico-pedagógico. sem a menor condição de receber crianças para um trabalho educacional - compunham um programa em que a precariedade material reproduzia as condições de vida da população neles atendida.

Uma filosofia "assistencialista" presidiu durante longos anos o programa e era viabilizada sobretudo pelas características "semipúblicas" do mesmo. Este talvez seja o principal elemento crítico e que se coloca no centro da discussão que pretendo travar. A não-caracterização plena de tais espaços educacionais como instituições públicas permitia que relações dúbias se estabelecessem. Em vez de um programa educacional, um ideário de "desenvolvimento comunitário" pinçava as pessoas contratadas para trabalhar nas creches e escolas comunitárias (sempre moradoras locais) como integrantes de ações sociais diversas e não como profissionais de educação. ${ }^{19}$ Não havia qualquer ênfase na necessidade de desenvolver um trabalho pedagógico com padrões razoáveis de qualidade, mesmo que em condições materiais adversas.

Progressivamente, porém, a percepção de que aqueles espaços eram antes de tudo destinados ao trabalho educacional foi se constituindo, confrontandose com um discurso que destacava os aspectos políticos e/ou o comunitarismo do trabalho. A partir de 1987, uma nova direção começou a ser impressa ao programa, buscando contrabalançar as características acima descritas com a busca de transformá-lo em um programa de educação pré-escolar público. A estratégia adotada pretendia contrapor à vocação política uma regulamentação e um controle técnico-burocrático que contrabalançassem os interesses particularistas expressos na política partidária, nas práticas do clientelismo e do populismo predominantes em nosso meio. A motivação principal dessa busca de mudança encontrava-se na intenção de construir um real programa de atendimento educacional, em contraposição a uma concepção de desenvolvimento comunitário e participação como eixos norteadores

${ }^{19} \mathrm{O}$ próprio termo cunhado para designar funcionalmente estas trabalhadoras expressa esta situação: agentes comunitárias. 
da linha de ação adotada. Isto porque o discurso participativo e a noção de desenvolvimento comunitário, herdados de orientações promovidas pelo UNICEF, foram incorporados de uma maneira peculiar por um discurso "esquerdizante", que preconizava a valorização da "comunidade".

Inúmeras foram as resistências, internas e principalmente externas ao corpo técnico do programa, mas este não é objeto deste trabalho. Após cerca de 20 anos de existência, o programa de apoio a escolas e creches comunitárias da cidade do Rio de Janeiro configura-se hoje como uma grande rede de iniciativas escolares, espalhada pela maioria das favelas, ocupações irregulares e bairros populares. Consolidou-se como uma forma específica de atendimento por parte do poder público a uma demanda muito sensível da população mais pobre da cidade. Se há uma característica distintiva deste programa, além de seu baixo custo, é a baixa qualidade dos serviços que presta, a precariedade das instalações que utiliza, podendo ser definido como um atendimento de segunda classe para uma parcela da população que assim também é tratada nos demais aspectos das políticas públicas.

Também nos aspectos relativos a seus efeitos internos nas localidades atendidas, havia uma particularidade importante. Jamais as escolas comunitárias eram de fato apropriadas pelas supostas comunidades. O mais comum era que algum "dono" - indivíduo ou grupo - concentrasse o poder em torno da escola. Tal fato oferecia um poder discricionário muito importante aos "líderes comunitários" que intermediavam a relação da escola com o poder público. Dispondo de uma "mercadoria" extremamente valorizada nos contextos sociais das escolas, os criadores/ organizadores/gestores/líderes das escolas tinham a seu alcance um instrumento importante de controle e indução de fidelidade por parte de seus beneficiários. Por outro lado, estas "lideranças" locais, em muitas circunstâncias, integravam-se a redes de influência político-eleitoral que faziam dos escassos serviços públicos instrumentos de obtenção de prestígio privado para seus membros. Muitas foram as vezes em que atritos se estabeleceram entre o corpo técnico do programa,$^{20}$ os secretários de governo e lideranças comunitárias. Quase sempre, a equipe técnica procurava defender algum tipo de regra universal para procedimentos do Programa e estas regras esbarravam em interesses dos demais atores.

Pode-se, assim, dizer que pelo fato de se encontrarem menos institucionalizadas e imersas numa cultura cívica pouco afeita ao universalismo das regras democráticas, as escolas comunitárias terminavam por ser um serviço custeado publicamente, mas, ao menos parcialmente, privatizado por algumas elites políticas. Os secretários municipais que imprimiram tal sentido à administração da secretaria terminaram por se eleger ao parlamento municipal, em grande parte por conta dos laços que criaram a partir desse trabalho.

A descrição acima talvez não seja justa para com um número expressivo de escolas comunitárias que destoavam do quadro acima caracterizado. Gostaria, sobretudo, de ressaltar que uma tentativa de reorientar o programa numa direção mais pública e institucionalizada, ao longo de 1987 e 1988, contou com apoio entusiástico de um bom número de profissionais que atuavam nas bases do mesmo. Por outro lado, algumas dessas pré-escolas realizavam um trabalho educacional digno de elogios, não apenas no que diz respeito ao cuidado com as crianças, mas também com as preocupações acerca dos aspectos pedagógicos desenvolvidos, apesar das condições materiais quase sempre precárias. Várias lideranças locais exerciam, também, um papel bastante construtivo e estimulante.

\section{As novas propostas de gestão educacional e as lições do passado}

Conforme exposta inicialmente, minha intenção era, pelo resgate da experiência vivida, trazer elementos críticos às propostas educacionais atuais que

${ }^{20}$ Uma equipe central constituída para dar suporte técnicopedagógico às profissionais que trabalhavam no campo, a qual foi adquirindo papel importante na tentativa de normatização e enquadramento do trabalho em padrões de qualidade razoáveis. 
enfatizam a gestão local e a parceria com grupos e ou instituições fora do estado como o elemento mais importante da "revolução educacional" que pretendem estar promovendo. Para tais propostas, a inépcia estatal seria uma característica congênita, bem como sua vocação excludente, dado que a burocracia estaria sempre voltada a extrair benefícios para si própria, mais que promover a democratização do acesso aos recursos e serviços que controla.

Neste ambiente, podem ser encontradas desde argumentações que destacam a má gestão dos recursos públicos, operada pela máquina estatal até a sucessão de evidências de negligência no interior dos sistemas educacionais públicos. Para estes males o antídoto estaria numa combinação de introdução de mecanismos de competição, ${ }^{21}$ redimensionamento das burocracias educacionais nos níveis intermediários e centrais, deslocamento de parte das decisões e da gestão em direção às pontas do sistema e na busca de parcerias com organizações da sociedade civil. Em muitos casos, regimes especiais de trabalho ${ }^{22}$ são criados para o funcionalismo admitido para desenvolver tais atividades.

No caso brasileiro, podem ser destacados programas de dimensão nacional, como o PAE - Programa de Aumento de Escolaridade, ${ }^{23}$ que utiliza como veículo pedagógico tecnologia de educação à distância; 0 Programa Alfabetização Solidária, ${ }^{24}$ bem como dispo-

${ }^{21}$ Os procedimentos de avaliação centralizada estão entre os que se destacam em tais estratégias. Esta dimensão das atuais políticas educacionais, porém, escapa ao alcance do presente artigo.

${ }^{22}$ Por regimes especiais de trabalho, no momento presente, deve-se entender a redução dos direitos sociais que compõem a proteção ao trabalho, reduzindo, assim, os custos de contratação da mão-de-obra.

${ }^{23} \mathrm{O}$ PAE articula a participação de órgãos públicos (sustentação financeira e diplomação), empresas privadas e associações locais, sendo ainda concebido e gerado pedagogicamente numa empresa privada, ligada à maior empresa de comunicações do país, que vende seus serviços ao programa, o qual é administrado por uma ONG, no caso do Rio de Janeiro.

${ }^{24}$ Programa promovido pelo governo federal para alfabetização de adultos, contando com poucos recursos orçamentários e dependendo de doações e trabalho voluntário. sitivos legais e regulamentações do Ministério da Educação que exigem a criação de formas de gestão local nas redes educacionais públicas. ${ }^{25}$ Ao lado disso, inúmeros programas estaduais preconizam a descentralização da gestão, com maior ou menor apelo à participação dos atores locais. Prossegue, também, especialmente no segmento pré-escolar, o modelo de escolas comunitárias acima descrito. A denominação de público-não-estatal adquire algum destaque entre defensores do citado tipo de modelo educacional.

No caso da América Latina, alguns programas nacionais adquirem destaque, como o EDUCO (Educación con Participación de la Comunidad), em El Salvador; o Escuelas Autónomas na Nicarágua; o PEI (Proyectos Educativos Institucionales, na Colômbia); e o PRONADE (Programa nacional de Autogestión para el Desarrollo Educativo), na Guatemala. Todos se baseiam naquilo que chamam parceria com as comunidades locais e na flexibilização dos critérios de contratação de mão-de-obra e de exigência de condições físicas satisfatórias.

A experiência que pude acumular levou-me a cultivar uma visão bastante reticente quanto a iniciativas desse gênero.

Em primeiro lugar, se há o louvável movimento de integração à escola de setores sociais aos quais o acesso encontrava-se bloqueado, é inegável que essa expansão se dá em padrões muito inferiores àqueles que caracterizaram a integração dos setores médios. É difícil supor que a arregimentação de força de trabalho a título precário ou o relaxamento quanto aos critérios de titulação do professorado sejam capazes de promover padrões de qualidade razoáveis. A própria intenção e justificativa de tais programas - o suposto atendimento a demandas de um mercado de trabalho mais competitivo e refinado - confrontam-se com a realidade de mercados formais em que as clientelas de tais programas possuem cada vez mais remotas chances de ingresso, dada a redução acelerada do número de

${ }^{25}$ Especialmente nos processos de redistribuição dos recursos que compõem o Fundo Nacional de Desenvolvimento do Ensino Fundamental. 
postos de trabalho. Neste quadro realmente mais competitivo, as credenciais distribuídas pelos agentes educacionais "tradicionais" evidentemente gozam de muito maior prestígio.

Há, porém, outro aspecto importante a ser destacado. O suposto elemento distintivo de tais programas seria sua ênfase nos aspectos participativos, seja das comunidades locais, seja de grupos privados, seja, ainda, de associações civis (ONG's). A experiência com as escolas comunitárias na década de 1980 levou-me a pensar seriamente sobre as supostas virtudes de tal modelo. Independentemente de suas características de precariedade técnica e material, o bem público que tais iniciativas têm a oferecer é algo bastante valorizado: a chance de alguma escolarização num mundo com mercado de trabalho muito mais seletivo. A concessão de tal oportunidade, ao ser administrada por agentes privados (ONGs ou associações locais), confere um poder não desprezível aos atores que a controlam. O mesmo se passaria, obviamente, com atores inscritos no seio das máquinas estatais. Entretanto, para esses últimos, a existência de regras mais consolidadas e a possibilidade de controles por meio da burocracia instituída, ou, em última instância, pelo eleitorado, configuram limites bem mais estritos. Já com os controladores da oferta educacional "em parceria" estes controles são bem mais frouxos. O baixo nível de institucionalização conduz a que a ausência de regras - as quais são muitas vezes inegavelmente excessivas e limitadoras de processos mais criativos - permita que poderes ainda mais discricionários se exerçam. Era assim, por exemplo, quando, nas escolas comunitárias, presidentes de associações de moradores tentavam interferir no quadro profissional contratado, de forma a recrutar pessoas de seus laços pessoais de fidelidade (muitas vezes sem mínimas qualificações para as funções pedagógicas), ou ainda quando a oferta de vagas para crianças obedecia a critérios semelhantes. Podese argumentar que tais procedimentos são mais bem controlados ao nível local pelos mecanismos participativos. Contudo, desde a formulação da teoria das elites por Michels (1982), sabemos que a disposição dos meios de participação está longe de ser algo distribuído com mínima eqüidade. Redes de interesses se formam entre chefes locais e políticos administradores de tal forma que, sem a contra-influência burocrática das normas, regulamentos e seus fiéis cumpridores, ficamos muito longe de esquemas democráticos.

A concepção de democracia como participação, ainda que atraente em diversos aspectos, é bastante falha. Afinal, desde os primórdios da democracia moderna, a utopia do governo direto é algo cada vez mais distante. Modelos de delegação e representação se estabelecem e, sobretudo, regras e normas a serem seguidas por todos tornam-se a peça-chave dos sistemas democráticos. É difícil imaginar que em ambientes de baixíssima escolarização, participação em um mundo do trabalho muito extenuante, submetido a longos deslocamentos, com remuneração muito baixa e dispondo de condições de habitação e acesso a serviços elementares de maneira geral bastante precários, um número grande de indivíduos disponha de condições razoáveis para participar da gestão da escola de seus filhos independentemente de sua capacidade de intervir substantivamente nas questões a serem tratadas na gestão escolar. O mais provável - que minha experiência confirmou - é que alguns indivíduos, portadores de melhores condições de participação, detenham o controle sobre os processos de gestão locais, com capacidades de constrangimento e manipulação acima do que pode ser encontrado nos sistemas públicos "tradicionais".

Tal fenômeno tende a não ser destacado, pois o predomínio de um discurso unilateralmente crítico do estado, que acentua seus aspectos menos afeitos à idéia de eqüidade, parece predominar tanto nos meios acadêmicos brasileiros quanto nos ambientes mais propensos a se confrontar com as reformas implementadas pelo que se convencionou chamar neoliberalismo. Este discurso esquerdizante tem sido um destacado elemento de legitimação das propostas e políticas de cunho participativo em torno das atuais políticas educacionais. Escora-se ele numa concepção de democracia que despreza os elementos universais em favor de concepções particularistas. A que se pode atribuir tal postura? Talvez a um certo desprezo que as concepções 
de origem marxista cultivaram em relação a conquistas sociais classificadas como burguesas.

Este artigo não se propõe a desenrolar o novelo teórico brevemente sugerido acima. Apenas gostaria de acrescentar que, particularmente nas condições brasileiras, a participação conta com condições culturais - o que poderíamos denominar "cultura cívica" - bastante distintas de sociedades em que a tradição é bem menos centralista e excludente que aquela, talvez, legada por nossa tradição ibérica.

Pode ser útil estar alerta contra a impressão de novidade das propostas de gestão descentralizada, baseadas na existência de uma suposta esfera pública nãoestatal. Em nossas condições isto pode significar apenas a reedição de antigos esquemas clientelistas e fisiológicos.

MÁRCIO DA COSTA é professor adjunto na Faculdade de Educação da Universidade Federal do Rio de Janeiro, onde se doutorou, e consultor da Fundação Clemente Mariani. Publicou recentemente: Tempos de desesperança; roteiro para pensar a educação quando o futuro parece sombrio, Humanas (Porto Alegre, v. 24, n.1-2, p.186-200, 2001); Stimulating itizenship: can educational policy enhance civic culture? Educational Theory \& Practice
(Australia: Albert Park, v. 22, n.1, p.75-93, 2000); Avaliando impactos sociais de uma política educacional democrática, Estudos em Avaliação Educacional (São Paulo: Fundação Carlos Chagas, n.19, p. 25-55, 1999). Pesquisa atual, com financiamento do CNPq: "Educação e exclusão social; o sagrado sob acusação". E-mail: marcioc@pobox.com

\section{Referências Bibliográficas}

CUNHA, L. A., (1991). Educação, Estado e Democracia no Brasil. São Paulo: Cortez; Niterói: EDUFF; Rio de Janeiro: FLACSO.

HIRSCHMAN, Albert O., (1992). A retórica da intransigência. São Paulo: Companhia das Letras.

MARSHALL, T. H., (1967). Cidadania, classe social e status. Rio de Janeiro: Zahar Editores.

McGINN, (1992). Reforming educational governance: centralization/ decentralization. In: ARNOVE, ALTBACH and KELLY, (org.). Emergent issues in education. New York: SUNY Press.

MICHELS, Robert, (1982). Sociologia dos partidos políticos. Brasília: Editora UnB (original de 1914).

WAGNER, Peter, (1994). Liberty and discipline - a sociology of modernit. London/New York: Routledge. 
ferido a que es quien más educación tiene, más educación demanda y se apropia). Los avances obtenidos develan además, el entramado de aspectos subjetivos y objetivos de las distintas trayectorias de vida (familiar, laboral, de participación social) que puede dar cuenta de las decisiones educativas, así como aspectos críticos de la formación de los educadores. Al final del artículo se presentan aportes para una política educativa desde la perspectiva de la educación permanente.

\section{The situation of adult and youth} education in the Argentine Presents the design and present progress in the research project entitled "Structure of power, participation and education: a study of the situation of Adult and Youth Education in the context of neoconservatism, policies of adjustment and poverty", directed by Maria Teresa Sirvent. The objective of the research is to analyse the demand and supply of Adult and Youth Education in selected regions of the Argentine. Three regional research teams are engaged in the study. The purpose of the research is to describe and interpret the demand, to elaborate essential features for educational policy and pedagogical recommendations. The methodological approach combines the quantitative and qualitative with participative mechanisms. The development of the research process has allowed attention to be concentrated on the possibility of reproduction or of rupture in a) the situation of profound educational poverty (level of educational risk) in which $75 \%$ of the population over 15 years of age which has attended but no longer attends school finds itself and $b$ ) the principle of accumulative advance in education (referring to the fact that those who have most education, demand more education and make use of the opportunities created). The findings obtained also reveal the interaction of subjective and objective aspects of distinct life paths (family, work and social participation) which can account for educational decisions in addition to critical aspects in the formation of educators. In conclusion, contributions for an educational policy based on the perspective of lifelong education are presented.

Newton Duarte

As pedagogias do "aprender a aprender" e algumas ilusões da assim chamada sociedade do conhecimento.

$\mathrm{O}$ artigo considera a pedagogia das competências como uma das pedagogias do "aprender a aprender" e apresenta quatro posicionamentos valorativos contidos no lema "aprender a aprender": 1) é mais desejável a aprendizagem que ocorra sem a transmissão de conhecimentos por alguém; 2) o método de construção do conhecimento é mais importante do que o conhecimento já produzido socialmente; 3) a atividade do aluno deve ser impulsionada pelos interesses e necessidades do indivíduo; 4) a educação deve preparar os indivíduos para um constante processo de adaptação e readaptação à sociedade em acelerado processo de mudança. Defende que as pedagogias do "aprender a aprender" pertencem a um universo ideológico carregado de ilusões acerca da assim chamada sociedade do conhecimento e conclui apresentando cinco dessas ilusões.

The pedagogy of "learning to learn" and some illusions of the socalled knowledge society

This article considers the pedagogy of competencies as one of the pedagogies of "learning to learn" and presents four valuational propositions contained in the slogan "learning to learn": 1) learning which occurs without the transmission of knowledge by someone is the most desirable; 2) the method by which knowledge is constructed is more important than that knowledge already socially produced; 3) student activities should be inspired by the needs and interests of the individual; 4) education ought to prepare individuals for a constant process of adaptation and readaptation to a society in accelerated process of change. The article defends the position that the "learning to learn" pedagogies belong to an ideological universe charged with illusions about the socalled knowledge society and concludes by presenting five of these illusions.

Márcio da Costa

Criar o público não-estatal ou tornar público o estatal? Dilemas da educação em meio à crise do Estado Presentemente, diversificam-se as formas de distribuição de recursos e responsabilidades no que concerne às políticas educacionais. Particularmente nos países com menor grau de desenvolvimento econômico, tal âmbito de tradicional ação estatal tem sido objeto de apelos destacados e políticas de estímulo expressivo à participação comunitária. São programas de extensão ao acesso da escolaridade para populações até então privadas de tal benefício, enfatizando as alterações na forma de gestão, com base na participação comunitária. Tais programas alteram a trajetória cumprida pelos sistemas escolares em sua expansão em todo o mundo, no que diz respeito à concepção de atividade essencialmente estatal. A partir da reflexão sociológica, serão debatidas as argumentações que sustentam tal tipo de programa, supostamente mais democrático e includente. 
To create the non-state public or to make the state public?

The forms of distribution of resources and responsibilities with respect to educational policy are at present diversified. The scope of traditional state action has been the object of forceful appeals and policies of expressive encouragement to community participation, particularly in less economically developed countries. These find expression in programmes aimed at extending access to schooling to populations who until that time have been denied such benefits and emphasise alterations in management style based on community participation. Such programmes change the trajectory of expansion followed by school systems world-wide with regard to the conception of what constitutes essentially state activity. Based on this sociological reflection, the text discusses the arguments that sustain such types of programme which are taken to be more democratic and inclusive.

Regina Leite Garcia

\section{A busca da coerência: reflexões so- bre a produção do GT Educação Po- pular}

O texto problematiza as questões recorrentes na produção do GT Educação Popular: amorosidade, autopoiesis, processo de auto-eco-organização; nova organização a partir do caos - o tempo/relógio e o tempo/interesse coletivo; em defesa dos homens lentos; uma sociologia da história lenta; a relação prática/ teoria/prática; a reflexão epistemológica sobre quem, como, e onde é produzido o conhecimento; a segunda ruptura epistemológica que reaproxima a ciência e o senso comum; a dimensão auto-reflexiva da questão epistemológica; a chegada do estranho nas pesquisas em educação popular; a dúvida que leva ao novo: a crise da compreensão é nossa; os que não vêem porque não compreendem; a aceitação do outro como condição para a aceitação de si mesmo; compreender o compreender; a reescrita da história a partir do ponto de vista dos subalternos; narrativas perdidas na história oficial; o discurso oral; a hegemonia de uma lógica que silencia as lógicas do cotidiano; a religiosidade popular - responsabilidade compartilhada; solidariedade de preocupações. E o desafio que fica é: se o GT Educação Popular repudia a hierarquização dos saberes como formas de exercício de poder, se reconhece formas plurais de cultura resultado de visões de mundo que carregam diferentes lógicas, como passam os seus componentes a tecer o currículo em suas ações pedagógicas, seja dentro seja fora da escola, melhor dizendo, em que mudam suas ações político-pedagógicas?

\section{In the search for coherence: reflections on the production of the Working Group on Popular Education}

This texts sets out to problematise recurrent questions in the production of the Working Group on Popular Education: amorosity, 'autopoiesis', process of auto-eco-organisation; new organisation based on chaos - timel clock and time/collective interest; in defence of slow men; a sociology of slow history - the relation practicel theory/practice; the epistemological reflection on who, how and where knowledge is produced; the second epistemological rupture which brings science and common sense closer together again; the auto-reflexive dimension of the epistemological question - the arrival of outsiders in research in popular education - the doubt which leads to the discovery of the new - the crisis of understanding is ours - those who do not see because they do not understand; the acceptance of the other as a condition for self-acceptance; understanding understanding - rewriting history from the point of view of the subordinate; narratives lost in official history; oral discourse; the hegemony of a logic which silences the logics of daily life; popular religiosity - shared responsibility; solidarity of concerns. And the challenge which remains is if the Working Group on Popular Education repudiates the ranking of knowledge as a means of exercising power, if it recognises plural forms of culture giving rise to visions of the world which contain different logics, how do the group members begin to construct a curriculum in their pedagogical actions, either inside or outside the school, or rather, how do their political-pedagogical practices change?

Antônio Flávio Barbosa Moreira

A recente produção científica sobre currículo e multiculturalismo no Brasil (1995-2000): avanços, desafios e tensões

$\mathrm{O}$ artigo analisa a recente produção científica brasileira sobre currículo e multiculturalismo. Foram incluídos nessa produção os artigos publicados nos seguintes periódicos: Cadernos de Pesquisa, Revista Brasileira de Educação, Educação \& Realidade, Educação \& Sociedade e Educação em Revista, bem como os trabalhos apresentados nas Reuniões Anuais da ANPEd. O período focalizado foi de 1995 a 2000. Procurou-se identificar as temáticas abordadas, os principais pontos de vista defendidos, as influências teóricas mais significativas, os enfoques metodológicos, as contribuições e as lacunas. Discutiram-se, também, tensões e desafios observados na produção em pauta. Insistiu-se na importância do diálogo entre os autores 